\title{
EFEITO DO ÓLEO DE ARROZ NA RAÇÃO SOBRE A PRODUÇÃO E COMPOSIÇÃO QUIIMICA DO LEITE DE OVELHAS CORRIEDALE\#
}

\author{
EFFECT OF RICE OIL IN THE RATION ON THE PRODUCTION AND CHEMICAL \\ COMPOSITION OF CORRIEDALE SHEEP'S MILK
}

Pradieé, J. ${ }^{1}$, Ferreira, O.G.L. ${ }^{1 *}$, Osório, M.T.M. ${ }^{1}$, Corrêa, G.F. ${ }^{2}$, Kessler, J.D. ${ }^{1}$ y Gonçalves, M. ${ }^{1}$

1Departamento de Zootecnia. UFPEL. Pelotas, RS. Brasil. *oglferreira@gmail.com

${ }^{2}$ Centro de Ciências Agrárias. Unipampa. Dom Pedrito, RS. Brasil.

PalaVRas chaVe adicionais

Dieta. Gordura. Lactação.

\section{RESUMO}

Foi avaliada a influência da adição de óleo de arroz, sobre a produção e a composição química do leite de ovelhas Corriedale multíparas alimentadas com ração comercial sem e com adição de óleo de arroz contendo respectivamente $4,36 \%$ e $6,56 \%$ de extrato etéreo. A ordenha mecânica foi realizada uma vez por semana, pela manhã. Além da produção de leite foram avaliados: gordura, proteína, lactose e sólidos totais. A produção de leite, bem como dos componentes químicos lactose, proteína, gordura e sólidos totais, não foram influenciadas pelo aumento do extrato etéreo da ração com a adição de óleo de arroz.

\section{SUMMARY}

It was evaluated the influence of rice oil addition on the milk production and chemical composition, of Corriedale multiparous sheep fed commercial diet with and without rice oil addition, containing $4.36 \%$ and $6.56 \%$ of ether extract, respectively. The mechanical milking was done once a week in the morning. Besides milk production the following components were evaluated: fat, protein, lactose and total solids. The milk production, as well the chemical components as lactose, protein, fat and total solids, were not influenced by diet increase of ether extract through rice oil addition.

"Projeto financiado pelo edital Casadinhos/ FAPERGS. Parte da dissertação de mestrado da primeira autora.

Recibido: 10-1-11. Aceptado: 8-2-11.

\section{ADDITIONAL KEYWORDS}

Diet. Fat. Lactation.

\section{INTRODUÇÃO}

A utilização de gordura na dieta animal, através da adição de óleos vegetais, constitui-se em uma prática nutricional bastante utilizada, podendo proporcionar diversos benefícios aos ruminantes de alta produção. As gorduras podem aumentar a densidade energética da dieta, melhorar a eficiência energética da produção de leite, conter ácidos graxos essenciais e melhorar a absorção de compostos lipossolúveis. Também têm potencial para melhorar a eficiência de utilização da energia, já que os ácidos graxos de origem dietética pré-formados são incorporados diretamente na gordura do leite sem a perda por incremento calórico associada à sua síntese. Há então, economia de energia para outras funções produtivas da glândula mamária, melhorando a eficiência na produção de ATP a partir de ácidos graxos de cadeia longa em comparação ao acetato, fonte energética fundamental nos ruminantes (Doreau et al., 1991; Chilliard, 1993; Garnsworthy, 1997). Na escolha da gordura a ser utilizada, fatores como preço e características da mesma devem ser contemplados. Como o sul do Rio Grande do Sul possui um dos maiores pólos beneficiadores de arroz da América Latina, o óleo de arroz, que provém do subproduto industrial farelo de arroz integral, é o de 
maior oferta na região, apresentando deste modo preço aceitável à sua utilização como componente de rações. O objetivo deste estudo foi avaliar a influência do aumento do extrato etéreo da ração, com a adição de óleo de arroz, sobre a produção e a composição química do leite de ovelhas Corriedale.

\section{MATERIAL E MÉTODOS}

O experimento foi realizado em outubro e novembro de 2007, no Centro Agropecuário da Palma, Universidade Federal de Pelotas, município de Capão do Leão, RS $\left(31^{\circ} 52^{\prime} \mathrm{S}\right.$ e $\left.52^{\circ} 29^{\prime} \mathrm{W}\right)$. Foram utilizadas ovelhas da raça Corriedale, multíparas, as quais nunca haviam sido ordenhadas. Os animais foram acasalados em abril de 2007, através de monta controlada e os partos ocorreram em setembro do mesmo ano.

Após a parição as ovelhas foram alocadas aos tratamentos ração comercial padrão e ração comercial com adição de óleo de arroz (Oriza sativa L.), com uma semana de adaptação. A composição bromatológica das mesmas é descrita na tabela I. A ração era composta de farelo de arroz desengordurado, milho moído, farelo de soja, casca de soja moída, calcário calcítico, cloreto de sódio (sal comum), premix mineral vitamí-

Tabela I. Composição (\%) das rações comercial padrão (CP) e comercial com adição de óleo de arroz (CA) e da pastagem nos meses de outubro e novembro. (Composition (\%) of commercial diets with (CA) and without (CP) addition rice oil and pasture composition in October and November).

\begin{tabular}{lcccc}
\hline & \multicolumn{2}{c}{ Ração } & \multicolumn{2}{c}{ Pastagem } \\
& CP & CA & out & nov \\
\hline Matéria seca & 87,58 & 89,58 & 22,83 & 29,82 \\
Proteína bruta & 18,27 & 17,61 & 14,04 & 10,70 \\
Extrato etéreo & 4,36 & 6,56 & - & - \\
FDN & 34,12 & 35,19 & 60,29 & 66,50 \\
FDA & - & - & 24,39 & 22,92 \\
Matéria mineral & 13,62 & 12,98 & 10,74 & 8,55 \\
& & & & \\
\hline
\end{tabular}

nico. Enriquecimentos: Vit. A: $12000 \mathrm{UI} / \mathrm{kg}$, Vit. D3: $3000 \mathrm{UI} / \mathrm{kg}$, Vit. E: $10 \mathrm{mg} / \mathrm{kg}, \mathrm{Zn}: 28$ mg, Mn: $44 \mathrm{mg}$, Co: 0,5 mg, Fe: 50 mg, I: 1,0 $\mathrm{mg}$ e Se: $0,15 \mathrm{mg}$. A mesma era ofertada no início da manhã e no final da tarde com disponibilidade média de $0,4 \mathrm{~kg} /$ animal $/$ oferta, totalizando $0,8 \mathrm{~kg} /$ animal $/$ dia, conforme o estado fisiológico e necessidades diárias baseadas no NRC (1985). Após, os animais eram liberados para o pastejo de Lolium multiflorum Lam. cv. La Estanzuela consorciado com Trifolium repens L. e Vicia sativa L. A composição bromatológica da pastagem é descrita na tabela I.

A ordenha mecânica foi realizada durante os meses de outubro e novembro, uma vez ao dia, no período da manhã $(7 \mathrm{~h})$, a cada 7 dias, totalizando oito coletas de leite. Os cordeiros eram separados das mães 12 horas antes da ordenha, a qual era precedida da aplicação de ocitocina injetável (15 U.I. $\mathrm{IM} /$ animal) e da lavagem dos tetos e secagem com papel toalha. Utilizou-se uma ordenhadeira com teteiras para ovinos com vácuo de $44 \mathrm{kPa}$ e 90 pulsações/minuto, conforme recomendação do fabricante (Westfalia Surge $^{\circledR}$ ) para esta espécie.

A avaliação da produção de leite em 12 horas foi realizada através da pesagem do conteúdo total de esgotamento da glândula mamaria de cada ovelha. Na correção da produção para 24 horas utilizou-se metodologia citada por Benson et al. (1999). Para a avaliação da composição química (proteína, lactose, gordura e sólidos totais) a cada ordenha coletava-se $5 \mathrm{~mL}$ de leite, que era acrescido de conservante Bromopol ${ }^{\circledR}$ e enviado ao Laboratório de Qualidade de Leite da EMBRAPA Clima Temperado.

Utilizou-se o delineamento completamente casualizado com dez repetições e análise de variância e comparação de médias pelo teste $\mathrm{F}(\mathrm{p}>0,05)$, através do procedimento GLM do SAS (Littell et al., 2002).

\section{RESULTADOSEDISCUSSÃO}

Era esperado que a produção de leite

Archivos de zootecnia vol. 61, núm. 233, p. 154. 
aumentasse com a elevação do extrato etéreo da ração, tendo em vista o aporte energético da gordura em relação às proteínas e carboidratos $(2,25 \%)$ e a inexistência de perdas por incremento calórico de seu metabolismo. Entretanto, apesar da elevação em $50,4 \%$ no extrato etéreo da ração pelo uso de óleo de arroz, não foram observadas diferenças significativas $(\mathrm{p}>0,05)$ entre os tratamentos para nenhum dos atributos analisados. Segundo Cannas e Avondo (2002), ovelhas que tem maior potencial genético para produção leiteira respondem melhor ao incremento de energia na dieta, em termos de produção de leite e gordura, do que ovelhas de baixo potencial. Como a raça Corriedale não é típica produtora de leite, isto provavelmente justificaria a não diferença entre os tratamentos no presente estudo. Entretanto, verifica-se que os valores obtidos (tabela II) encontram-se dentro do esperado para a raça (Souza et al., 2005; Corrêa et al., 2008).

Quanto à produção de lactose, obtevese percentual médio para os tratamentos ração comercial com adição de óleo de arroz e ração comercial padrão respectivamente de 6,06 e $6,71 \%$, proveniente de uma produção média de $2,61 \mathrm{~kg}$ (tabela II). Embora a diferença entre os tratamentos não tenha sido significativa, os resultados vão ao encontro de trabalhos em que a elevação dos níveis de extrato etéreo na dieta tem causado diminuição nos teores de lactose (Sinclair et al., 2007). Os valores observados se encontram próximos aos 5,3\% obtidos por Corrêa et al. (2008) e aos 6,92\% observados no leite humano (Saini e Gill. 1991), permitindo a substituição deste último por leite ovino sem os problemas de intolerância a lactose. Porém é importante que não seja confundida intolerância a lactose com alergia a proteína do leite, que neste caso também ocorreria.

Em relação à produção de proteína, a ausência de diferenças entre os tratamentos (tabela II) se deve ao fato das dietas terem valores protéicos muito próximos, embora segundo Jenkins (1993), este componente seja o que mais varia por influencia da alimentação, e seu metabolismo seja alterado pela suplementação de gordura.

A produção de gordura apresentou média de $2,77 \mathrm{~kg}$ (tabela II). Os teores médios dos tratamentos ração comercial com adição de óleo de arroz e ração comercial padrão foram respectivamente 7,11 e $6,45 \%$, valores dentro da amplitude verificada por Casoli et al. (1989). Em bovinos a adição de gordura na dieta pode diminuir a síntese de gordura na glândula mamária (Palmquist e Jenkins, 1980). Porém em ovinos, o critério para o efeito da energia na dieta segue o já citado por Cannas e Avondo (2002), sob o qual ovelhas de maior potencial genético para produção leiteira respondem melhor ao incremento de energia. A elevação na produção de gordura do leite, normalmente é acompanhada da redução de seu teor, tendo em vista a diluição ocorrer em maior quantidade de leite produzido. Por sua vez, o adequado consumo de volumoso proporcionaria no leite um teor normal de gordura, pois através da fermentação da fibra no rúmen são produzidos os ácidos graxos voláteis, acético e butírico, que originam no úbere $50 \%$ da gordura do leite.

$\mathrm{Na}$ produção de sólidos totais, a

Tabela II. Média e desvio padrão da produção $(\mathrm{kg})$ de leite e dos componentes químicos para cada tratamento. (Mean and standard deviation of production $(\mathrm{kg})$ and chemical composition of milk for the treatments).

\begin{tabular}{lccr}
\hline & \multicolumn{2}{c}{ CP } & \multicolumn{2}{c}{ CA } & Média \\
\cline { 2 - 4 } $\begin{array}{l}\text { Produção de } \\
\text { leite }\end{array}$ & $41,65 \pm 1,5$ & $40,26 \pm 1,5$ & $40,95 \pm 1,5$ \\
lactose & $2,75 \pm 0,1$ & $2,48 \pm 0,1$ & $2,61 \pm 0,1$ \\
proteína & $2,70 \pm 0,1$ & $2,68 \pm 0,1$ & $2,69 \pm 0,1$ \\
gordura & $2,64 \pm 0,1$ & $2,91 \pm 0,1$ & $2,77 \pm 0,1$ \\
sólidos totais & $8,84 \pm 0,4$ & $8,73 \pm 0,4$ & $8,78 \pm 0,4$
\end{tabular}

CP: Ração comercial padrão; CA: Ração comercial com adição de óleo de arroz.

Médias não diferem estatisticamente pelo teste $F$. 


\section{PRADIEÉ, FERREIRA, OSÓRIO, CORRÊA, KESSLER E GONÇALVES}

igualdade entre os tratamentos (tabela II) está ligada a ausência de diferença nas variáveis de qualidade já discutidas. Com o aumento do teor de gordura na dieta, esperava-se que aumentassem todos os componentes sólidos do leite, fato que não ocorreu. Os teores médios para os tratamentos ração comercial com adição de óleo de arroz e ração comercial padrão foram respectivamente de 21,32 e $21,6 \%$. A importância do conhecimento do teor de sólidos do leite, principalmente gordura, proteína e lactose, está na correlação com o rendi-

\section{BIBLIOGRAFIA}

Benson, M.E., Henry, M.J. and Cardellino, R.A. 1999. Comparison of weigh-suckle-weigh and machine milking for measuring ewe milk production. J Anim Sci, 77: 2330-2335.

Cannas, A. and Avondo, M. 2002. Relationships among milk fat content, energy balance and NDF intake in lactating ewes fed at pasture. Proc. 53 ${ }^{\text {rd }}$ Annual Meeting of European Association of Animal Production. Cairo. pp. 55.

Casoli, C., Duranti, E., Morbidini, L., Panella, F. and Vizioli, V. 1989. Quantitative and composition variations of Massese sheep milk by parity and stage of lactation. Small Ruminant Res, 2: 4762.

Chilliard, Y. 1993. Dietary fat and adipose tissue metabolism in ruminants, pigs, and rodents: a review. Symposium advances in ruminant lipid metabolism. J Dairy Sci, 76: 3897-3931.

Corrêa, G.F., Osório, M.T.M., Perdigón, F., Sosa, L., Kremer, R., Osório, J.C.S., Silva, J.G.C. e Lopes, P.R.S. 2008. Produção e composição química do leite de ovelhas Corriedale com diferentes níveis de suplementação aos 100 dias de lactação. Rev Bras Agroci, 14: 339-347.

Doreau, M., Chilliard, Y., Bauchart, D., MichaletDoreau, B., Fléchet, J., Lefaivre, R., Legay, C., Meyer, M. and Ollier, A. 1991. Influence of different fat supplements on digestibility and mento industrial para a produção de derivados lácteos, como o queijo e o leite em pó.

A produção de leite, bem como dos componentes químicos lactose, proteína, gordura e sólidos totais, não foram influenciadas pelo aumento do extrato etéreo da ração com a adição de óleo de arroz.

\section{AGRADECIMENTOS}

Ao CNPq pela concessão da bolsa de mestrado. À FAPERGS pelo financiamento do projeto e concessão da bolsa de recémdoutor.

ruminal digestion in cows. Ann Zootech, 40: 1930.

Garnsworthy, P.C. 1997. Fats in dairy cow diets. In: Garnsworthy, P.C., Cole, D.J.A. (Eds.). Recent advances in animal nutrition. University of Nottingham. Nottingham. pp. 87-103.

Jenkins, T.C. 1993. Lipid metabolism in the rumen. J Dairy Sci, 76: 3851-3863.

Littell, R.C., Stroup, W.W. and Freund, R.J. 2002. $\mathrm{SAS}^{\circledR}$ for Linear Models. $4^{\text {th }}$ ed. SAS Institute. Cary. 466 pp.

NRC. 1985. Nutrient requirements of sheep. $6^{\text {th }}$ ed Washington. National Academic Press. Washington. $99 \mathrm{pp}$.

Palmquist, D.L. and Jenkins, T.C. 1980. Fat in lactation rations: review. J Dairy Sci, 63: 1-14.

Saini, A.L. and Gill, R.S. 1991. Goat milk: An attractive alternate. Indian Dairyman, 42: 562564.

Sinclair, L.A., Lock, A.L., Early, R. and Bauman, D.E. 2007. Effects of trans-10, cis-12 conjugated linoleic acid on ovine milk fat synthesis and cheese properties. J Dairy Sci, 90: 3326-3335.

Souza, A.C.K.O., Osório, M.T.M., Osório, J.C.S. Oliveira, N.M., Vaz, C.M.S., Souza, M. e Corrêa, G.L.F. 2005. Produção, composição química e características físicas do leite de ovinos da raça Corriedale. Rev Bras Agroci, 11: 73-77. 